\title{
The histological diagnosis of chronic gastritis in fibreoptic gastroscope biopsy specimens
}

\author{
R. WhiteheAd, S. C. TRUELOVE, AND M. W. L. GEAR \\ From the Department of Morbid Anatomy and the Nuffield Department of Clinical Medicine, The \\ Radcliffe Infirmary, Oxford
}

SYNOPSIS The advent of the fibreoptic gastroscope with biopsy facilities has provided the means of obtaining biopsy specimens under direct vision from any part of the stomach. This creates new opportunities for the study of chronic gastritis, and, in particular, its evolution, topographical location, and causal relationships. On the basis of an experience with more than 2,500 biopsy specimens we have outlined a method for their systematic examination and have proposed a classification of chronic gastritis. This classification includes the type of mucosa, the type and stage of activity of the gastritis, and the presence and type of metaplasia. The classification is sufficiently flexible to allow within it quantitative assessment of individual histological features.

Knowledge concerning the evolution of chronic gastritis and its topographical distribution in the stomach during life is scant. It was with some justification that MacDonald and Rubin (1967) wrote: 'The definition and classification of chronic gastritis remains unsatisfactory.' Motteram (1951), for example, subdivided chronic gastritis into superficial gastritis with minimal atrophy, atrophic gastritis with moderate or severe atrophy, and gastric atrophy. Wood and Taft (1958) used the terms 'superficial, gastritis', 'atrophic' gastritis, and 'gastric atrophy'. The superficial gastritis of Williams, Edwards, Lewis, and Coghill (1957) was classified by others (Davidson and Markson, 1955) as mild atrophic gastritis. These and other classifications were based on the appearances in body mucosa, whereas Schrager, Spink, and Mitra (1967) used an entirely different classification for antral mucosa.

These variations in classification are partly due to inherent limitations in the methods of study which we have outlined in a separate paper (Gear, Truelove, and Whitehead, 1971). With the advent of fibreoptic gastroscopes equipped with biopsy facilities these limitations are largely overcome. It is now possible to obtain free from autolysis or operative artefact multiple, full-thickness biopsy specimens, ie, including muscularis mucosa, from all parts of the gastric mucosa at the same examination. The

'Present address: Gloucestershire Royal Hospital, Southgate, Gloucester.

Received for publication 28 June 1971. examination is easily performed and well tolerated, a combination lending itself admirably to the serial studies necessary for proper investigation of the evolution of chronic gastritis and its relationship to other conditions.

During an investigation of the relationship of chronic gastritis to gastric ulcer (Gear et al, 1971) the absence of a classification of chronic gastritis applicable to all areas of the gastric mucosa became obvious. This paper describes such a classification based on our experience with over 2,500 biopsy specimens, including material used in the study by Gear et al (1971), and additional material from patients with dyspepsia, duodenal ulcer, irondeficiency anaemia, pernicious anaemia, malabsorption syndromes, carcinoma of the stomach, and patients without detectable gastric disease.

\section{Methods}

Great care is necessary in the technical handling of these small biopsy specimens. Trauma is avoided if the jaws of the biopsy instrument are immersed in formol-saline contained in a shallow dish. The specimen floats or is shaken free and then examined under the dissecting microscope. If curled up it is gently uncurled with fine forceps and a dissecting needle and then transferred, mucosal surface uppermost, onto a strip of filter paper. Orientation is again checked stereo-microscopically before it is transferred - still on the filter paper, to which it will adhere- 
into further fixative in a suitable container. After fixation, the biopsy specimen (still on its piece of filter paper) is wrapped in a further piece of filter paper and processed in a perforated capsule. Before embedding, it is unwrapped, removed from the original filter paper, and embedded in wax with the mucosal surface uppermost. Four-micron sections cut perpendicular to this surface are then easily obtained, and several serial sections are mounted on each slide.

The following staining methods were employed: haematoxylin and eosin ( $\mathrm{H}$ and $\mathrm{E})$, periodic acidSchiff (PAS), Maxwell's method (1963), and a reticulin method (James, 1967).

\section{Results}

\section{NORMA L}

The pyloric glands occupy a roughly triangular area in the lower third of the stomach. On the greater curve they occur only in the immediate pyloric region but on the lesser curve the upper limit-whilst usually in the region of the incisura angularis-is more variable and rarely extends to the oesophagus. The cardiac glands are found distal to the cardiooesophageal junction for a distance of about $1 \mathrm{~cm}$ and the remaining mucosa is of body type. The junction between the three areas may be abrupt but is often occupied by a narrow transitional zone. At the pylorus-body junction in the lesser curve region the width of the transitional zone is variable and rarely the whole lesser curve shows a transitional appearance.

\section{Body mucosa}

This is shown in Figure 1. Throughout the stomach the superficial epithelium is a single layer of cells with a basal nucleus below a typical cup-shaped column of clear or faintly granular mucus. It dips to form shallow gastric pits, into which open approximately four gastric glands. These are simple straight tubules tightly packed together, roughly the same length, which occupy three-quarters of the thickness of the mucosa. The majority of cells lining the upper part of the glands are parietal cells. These are eosinophilic and triangular with a central nucleus. Their longest side is applied to the basement membrane and sometimes intracellular canaliculi are visible. At the junction of the glands with the pits, scattered amongst the parietal cells and sometimes deeper, there are the mucous neck cells which, like the superficial epithelium, contain PAS-positive and diastase-resistant mucus. The lower half of the glands contains the chief cells, which mingle with the parietal cells in the region of the middle third. Chief cells have a basal nucleus and a cytoplasm

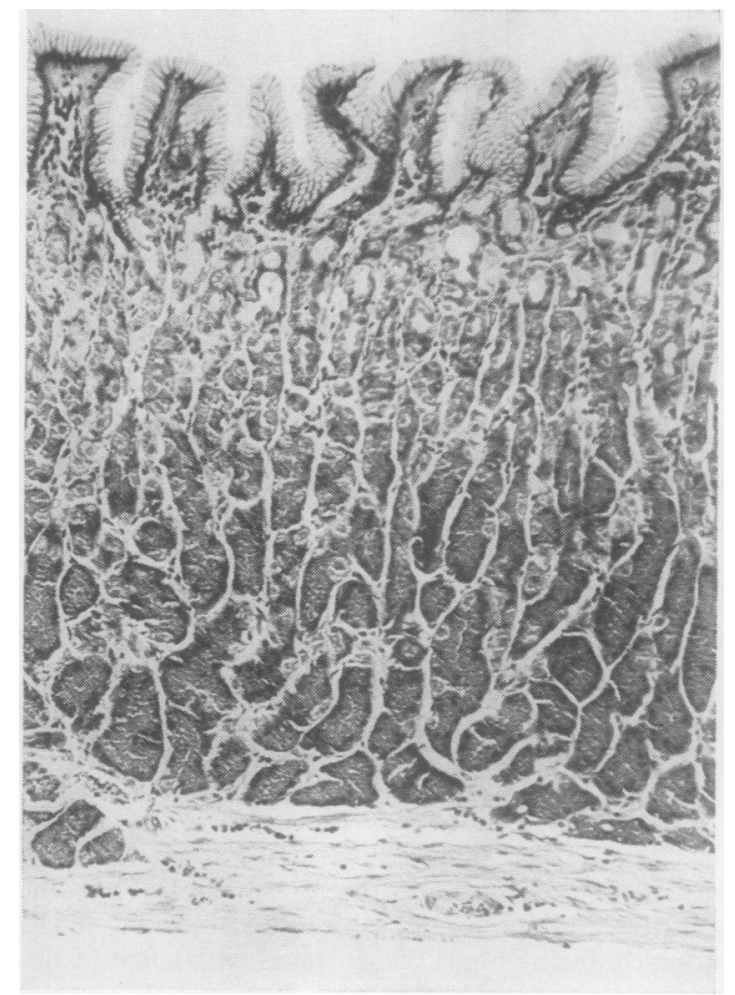

Fig. 1 Normal body mucosa ( $\times 50 \mathrm{H}$ and E).

filled with basophilic pepsinogen granules. The degree of basophilia of the granules varies from biopsy to biopsy. Occasionally towards the base there is an isolated argentaffin cell with its nucleus near the lumen of the gland and a strongly eosinophilic cytoplasm due to granules just too small to be resolved with the light microscope.

The lamina propria is most obvious between the gastric pits where it contains a small number of plasma cells, lymphocytes, eosinophils, and histiocytes, together with a fine capillary plexus and nonmyelinated nerves. At intervals along the mucosa the muscularis mucosa sends infrequent groups of smooth muscle fibres upwards between the glands. In reticulin preparations (Fig. 2) the basement membrane of the surface epithelium, pits, and glands appears as a single layer of fibres between which a delicate mesh of strands represents the supporting connective tissues between and in relation to the capillaries. The sharp division between the reticulin pattern of the lamina propria and the denser network around the fibres and vessels of the muscularis mucosa is broken only by occasional tent-shaped skeins of fibres which surround the upward muscular prolongations. 


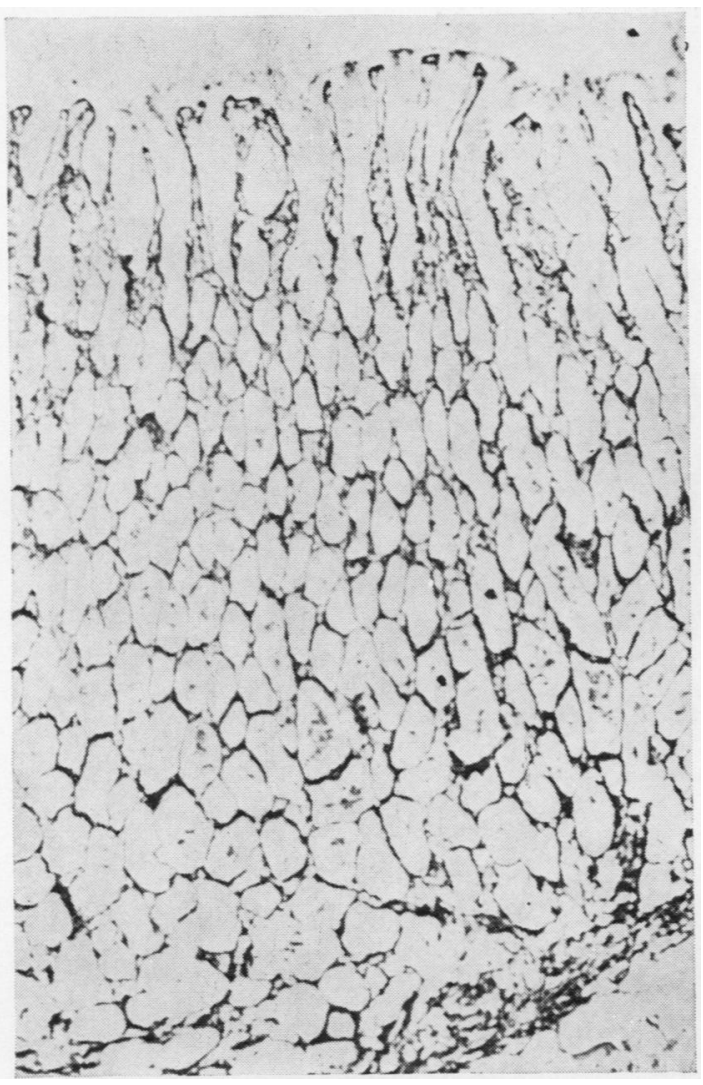

Fig. 2 Normal body mucosa ( $\times 50$ reticulin stain).

\section{Pyloric mucosa}

Figure 3 shows the appearances. Here the gastric pits are deeper and sometimes branched, the glands are shorter, less tightly packed than in the body, ending at different levels and occupying a half or less of the mucosal thickness. They are simple or branched coiled tubules, composed of mucussecreting cells and occasional parietal cells (Fig. 4) especially near transitional zones. Argentaffin cells are more frequent in this area than in the other areas of the gastric mucosa. The interdigitation of fibres from the muscularis mucosa is more marked and there is more intertubular reticulin so that the pattern is quite distinctive (Fig. 5).

\section{Cardiac mucosa (Fig. 6)}

This is essentially similar to the pyloric mucosa, except that the glands are even less tightly packed together. As a rule, parietal cells and argentaffin cells are absent. A characteristic feature is the presence of one or more dilated or cystic glands with a thin epithelial wall.

\section{Transitional mucosa (Figs. 7 and 8)}

This is composed of both body and pyloric or cardiac type glands. Like pyloric and cardiac mucosa the pits occupy about one half of the mucosal thickness.

Recent electron microscopic and histiochemical studies have shown that in addition to argentaffin cells several other endocrine polypeptide cells are present in the gastric mucosa. Pearse, Coulling, Weaver, and Friesen (1970) summarize present knowledge of these specialized cells which are not considered in this present study.

\section{Changes seen in chronic gastritis}

Because the various grades of chronic gastritis are probably different stages in one dynamic process, it seemed logical that the histological changes in gastritic mucosae should be considered together. In

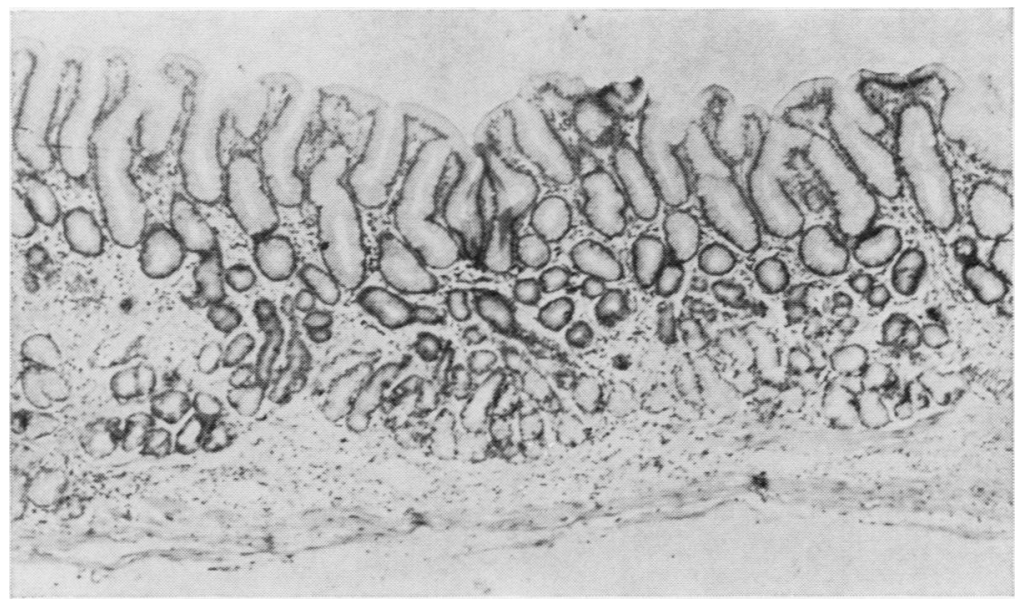

Fig. 3 Normal pyloric mucosa $(\times 50 \mathrm{H}$ and $\mathrm{E})$. 
Fig. 4 Normal pyloric mucosa, parietal cells (arrows) ( $\times 400 \mathrm{H}$ and $E$ ).

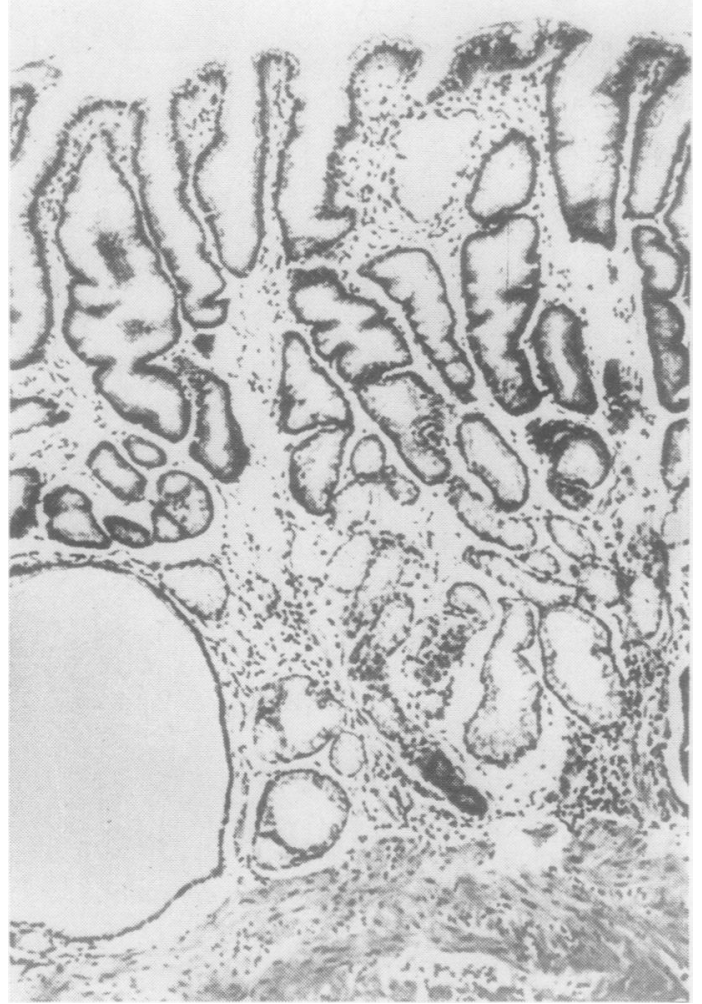

Fig. 6 Normal cardiac mucosa ( $\times 50 \mathrm{H}$ and $\mathrm{E}$ ).

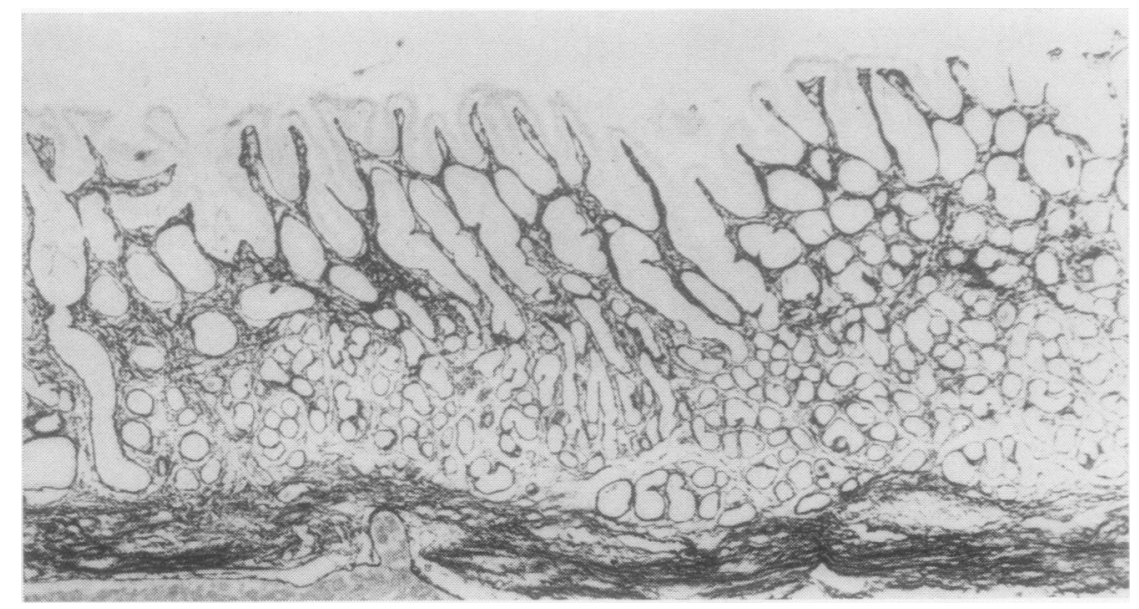

Fig. 5 Normal pyloric mucosa ( : 30 reticulin stain). 


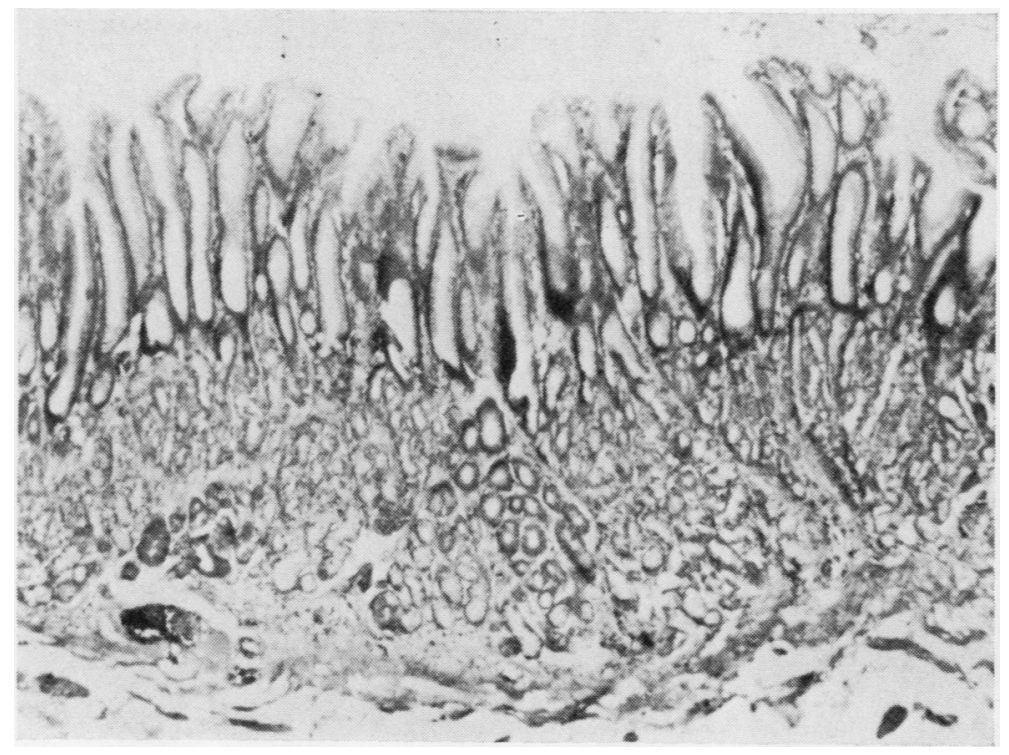

Fig. 7 Normal transitional mucosa. Mixed body and pyloric glands with pits of 'pyloric' length ( $\times 50 \mathrm{H}$ and $\mathrm{E})$.

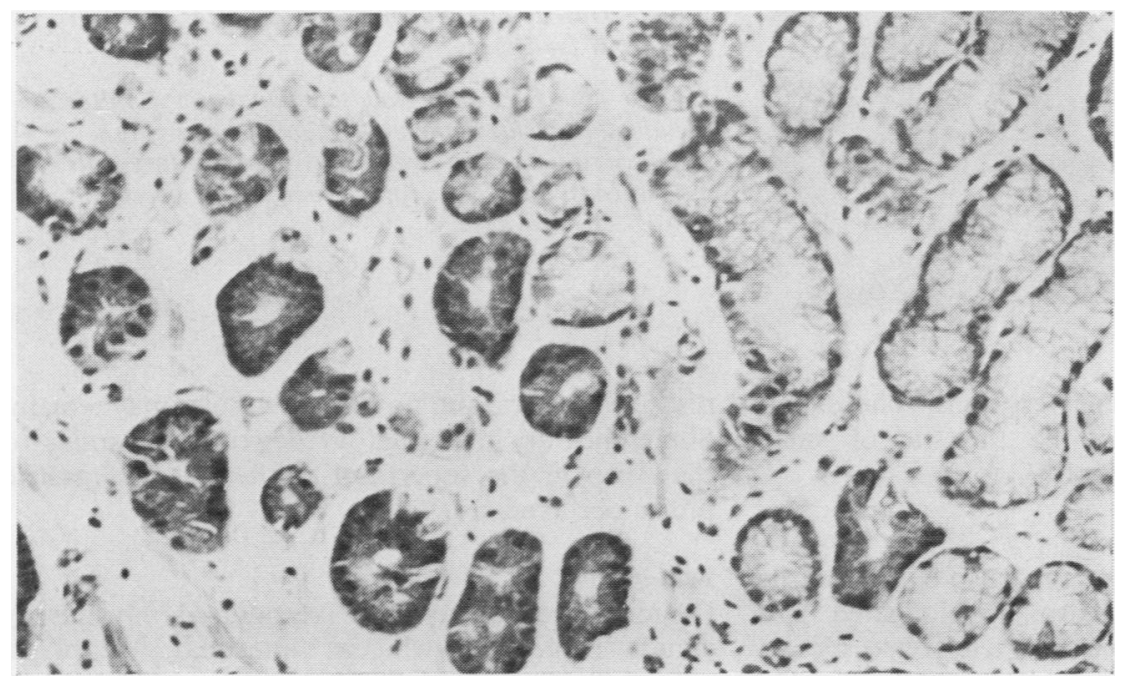

Fig. 8 Detail of Fig. 7 showing both pyloric (left) and body (right) glands ( $\times 100 \mathrm{H}$ and $\mathrm{E}$ ).

this way the criteria for classifying gastritis are established with a minimum of preconceived notions.

In turn, the different components of the mucosa should be assessed and variations from normal carefully noted.

\section{Superficial epithelium}

The superficial epithelium may show features suggesting both degenerative and regenerative processes. The cells may appear flattened or cuboidal with hyperchromatic nuclei, partial or complete loss of the mucous column, and increased basophilia of the diminished cytoplasm. The cells may form a layer several cells in thickness, their limiting membranes becoming blurred and indistinct so that bud-like syncytial masses are formed. When degenerative changes are most marked the epithelium may show invasion by polymorphonuclear leucocytes and occasional lymphocytes sometimes appearing within vacuolar spaces between the epithelial cells. This constitutes a striking picture suggestive of an active inflammatory destruction of the epithelium and may 


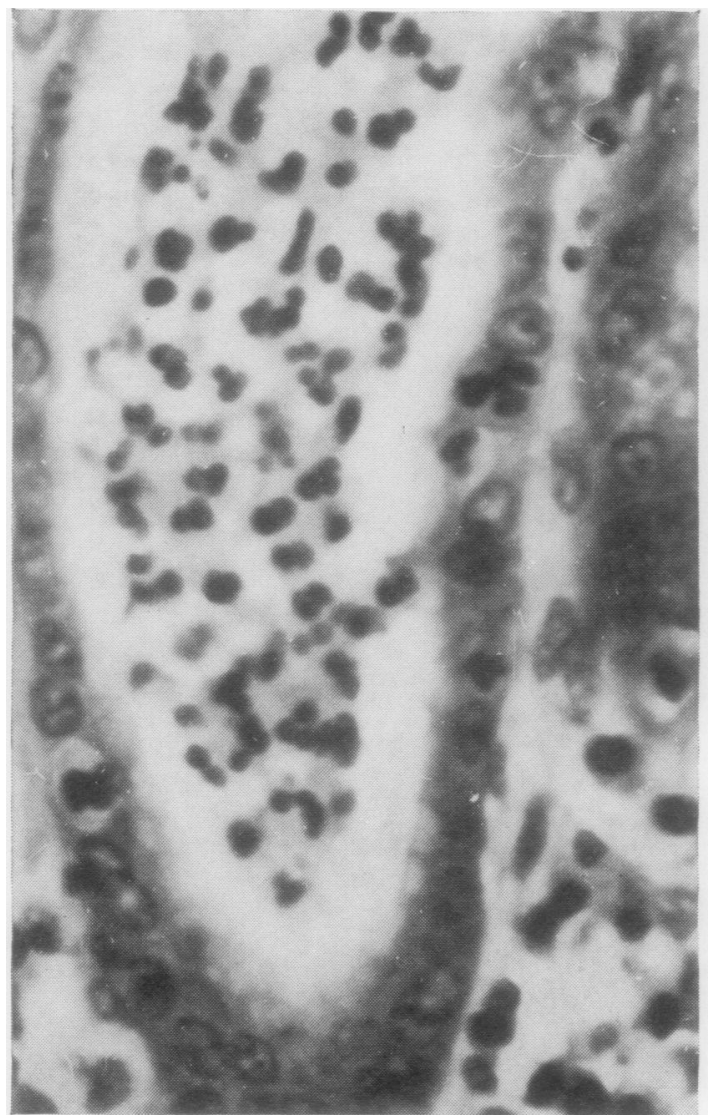

Fig. 9.

be associated with epithelial erosions. The superficial epithelium may also be the site of small intestinal metaplasia (vide infra).

\section{Pits}

The above epithelial changes may also be seen in the gastric pits, which may also be elongated and tortuous so that they appear in transverse section more frequently than normal. Polymorph invasion of the crypt epithelium and collections of polymorphs in the dilated lumen (Fig. 9) mimic the appearance of a crypt abscess in ulcerative colitis. The pits are sometimes separated by inflammatory oedema of the lamina propria and appear reduced in number, but a reduction may also result from shrinkage and degenerative atrophy.

\section{Gland tubules}

The gland tubules may remain normal despite severe changes in the superficial epithelium and gastric pits. Frequently, however, groups of tubules shrink or disappear completely. The number which

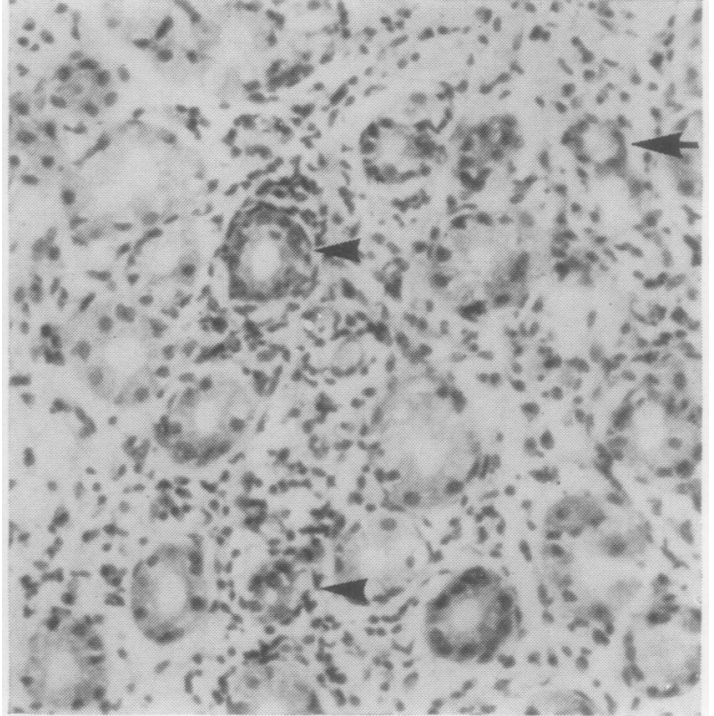

Fig. 10.

Fig. 9 Gastric pits. Polymorph aggregates in lumen ( $\times 400 \mathrm{H}$ and $\mathrm{E}$ ).

Fig. 10 Body mucosal glands. Inflammatory infiltration of lamina propria. Some gland tubules (arrow) are shrunken, others show invasion by inflammatory cells (arrowheads) and degenerative changes of component cells $(\times 100 \mathrm{H}$ and $\mathrm{E})$.

disappear varies, and no normal tubules may remain. Sometimes an inflammatory destruction similar to that seen in the superficial epithelium and gastric pits is observed (Fig. 10).

\section{Metaplasia}

Pseudo-pyloric metaplasia is recognized only in body glands (Fig. 11), whereas intestinal metaplasia affects all types of glands, the superficial epithelium, and pits. The earliest stage of pseudo-pyloric metaplasia consists of an increase in mucous neck cells which later replace the remaining specialized cells in the rest of the tubule, so that the appearance mimics normal pyloric glands. This may reflect deficient differentiation whereby the mucous neck cells descend into the gastric glands and become peptic and parietal cells. When there is intestinal metaplasia epithelial cells of small-intestinal type, including absorptive cells in various stages of maturation, goblet cells, and Paneth cells, can be recognized. Argentaffin cells are also present in increased numbers. Sometimes structures covered by 


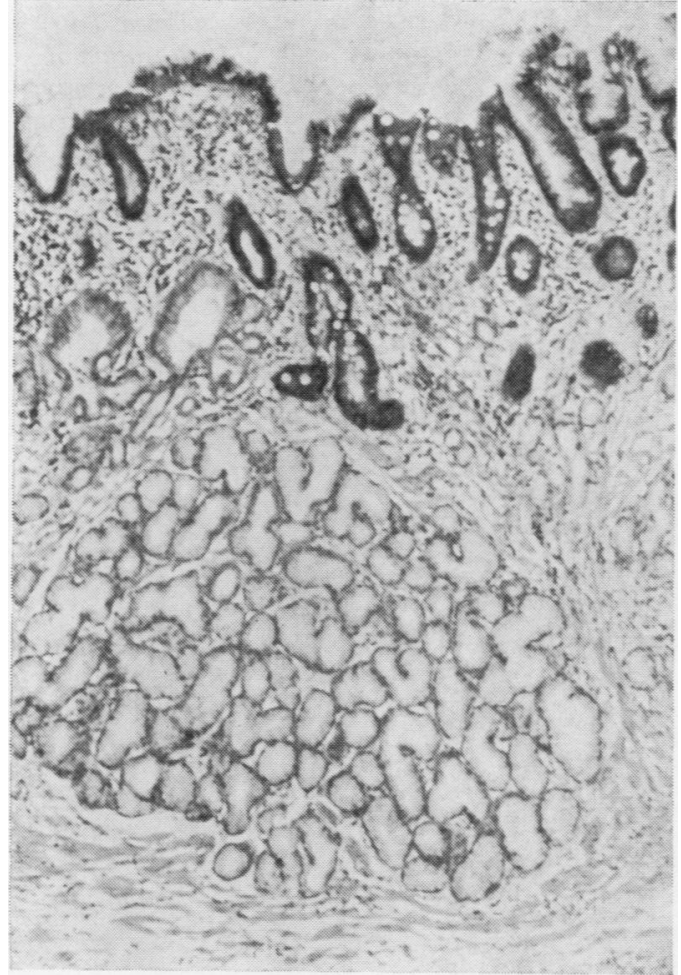

Fig. 11 Body mucosa. Intestinal metaplasia of surface epithelium and pits. Pseudo-pyloric metaplasia of glands ( $\times 50 \mathrm{H}$ and $\mathrm{E}$ ). intestinal epithelium project from the surface thus simulating intestinal villi (Fig. 12).

\section{Lamina propria}

The lamina propria may show an inflammatory infiltrate which includes plasma cells, lymphocytes, and eosinophil and neutrophil polymorphs. Neutrophil polymorphs or a mixture of lymphocytes and plasma cells may predominate. The infiltrate may be restricted to a part or the whole of the area between the gastric pits, and in addition may involve part or the whole of the deeper parts. A polymorph-rich infiltrate is commonly associated with vascular dilatation and a sero-fibrinous oedemawith destructive inflammation of the related epithelium. When chronic inflammatory cells predominate plasma cells are seen in the upper layers and lymphocytes in the lower layers where follicular aggregates with or without germinal centres may form. In mucosa with only minimal epithelial degenerative changes or widespread atrophy and metaplasia, the inflammatory infiltrate is often very scanty and always of the type in which plasma cells or lymphocytes preponderate. Foci of fatty infiltration may appear in the lamina propria and in any lymphoid follicles present which also appear atrophic (Fig. 13).

The reticulin fibres may appear more widely spaced than normal when there is inflammatory oedema. A more frequent change is seen in association with atrophy (Figs. 14 and 15). Under the superficial epithelium and in the inter-pit and inter-

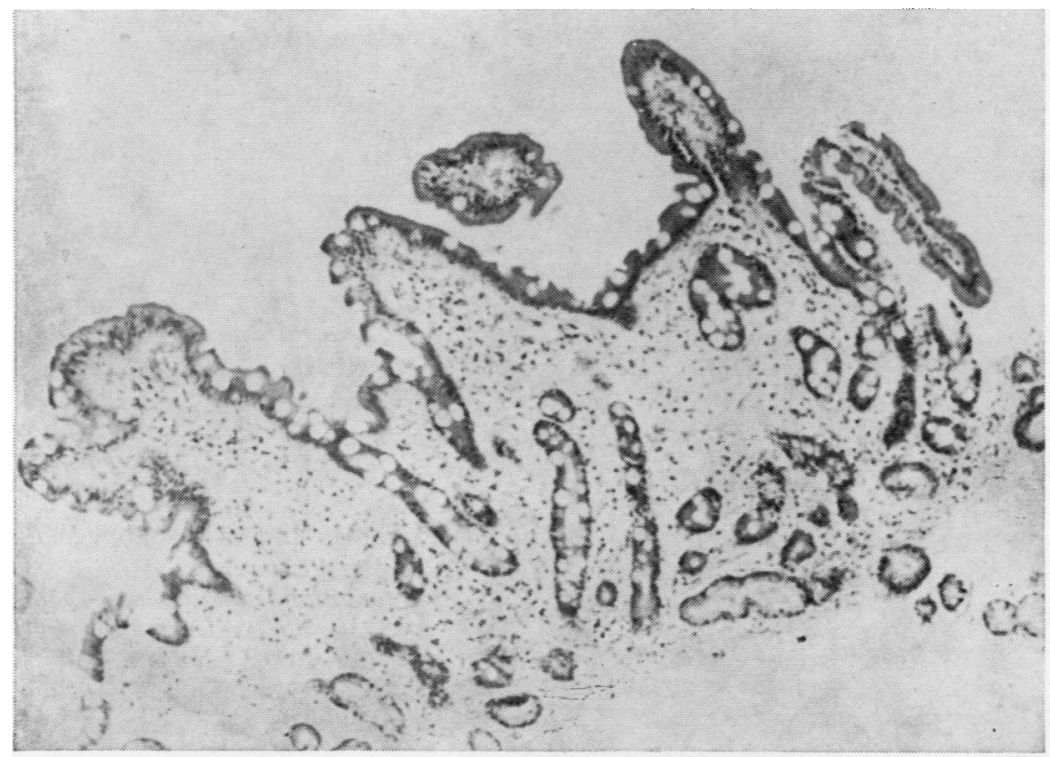

Fig. 12 Pyloric mucosa. Intestinal metaplasia and pseudo-villi ( $\times 50 \mathrm{H}$ and $\mathrm{E}$ ). 


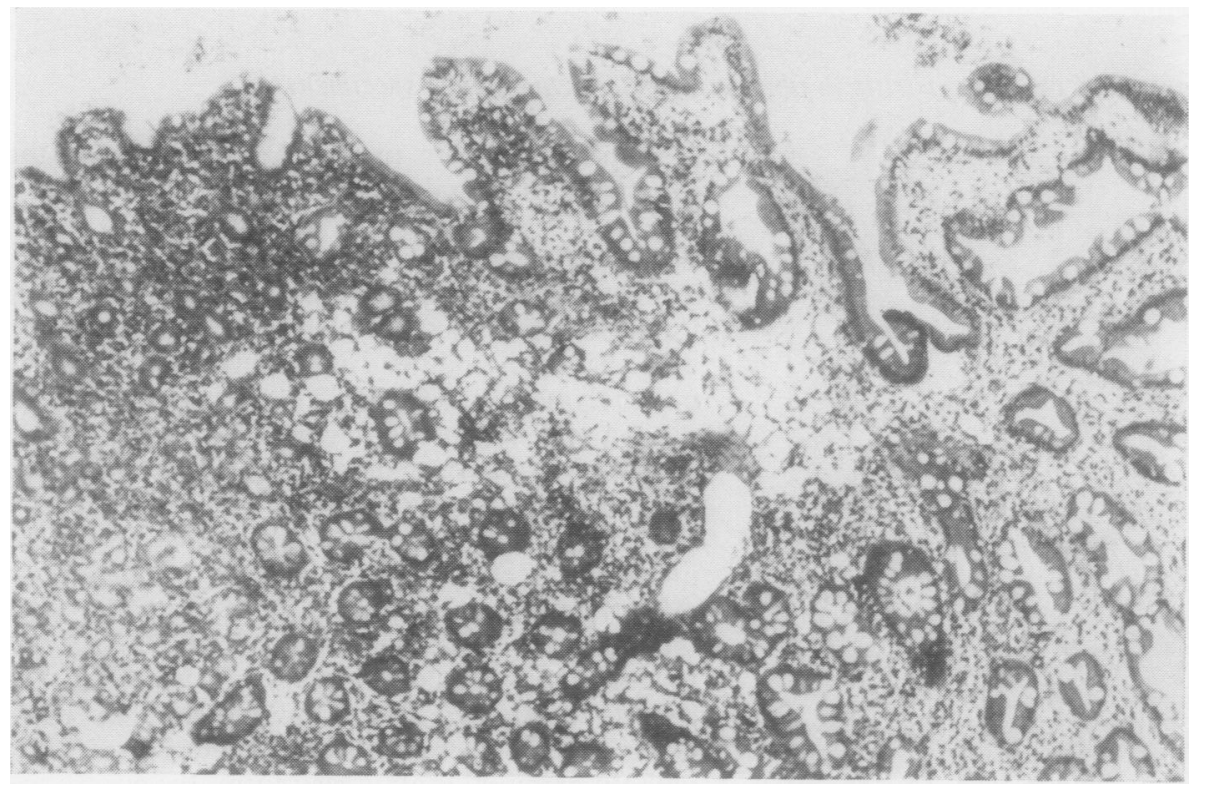

Fig. 13 Body

mucosa. Fatty

infiltration of

lamina propria

and widespread

intestinal

metaplasia

$(\times 100 \mathrm{H}$

and $E$ ).

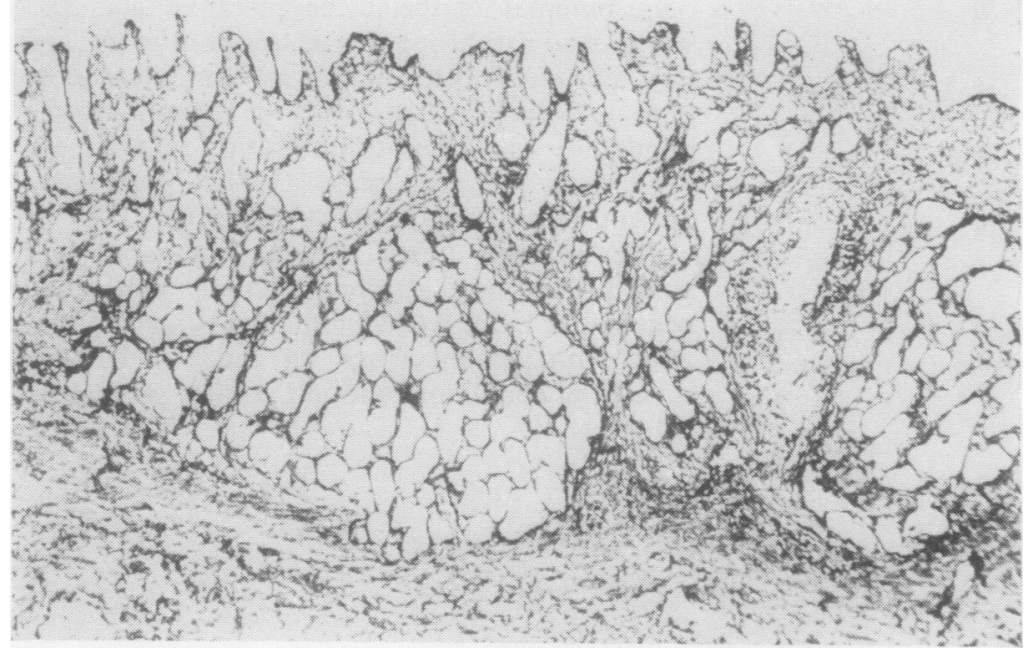

Fig. 14.

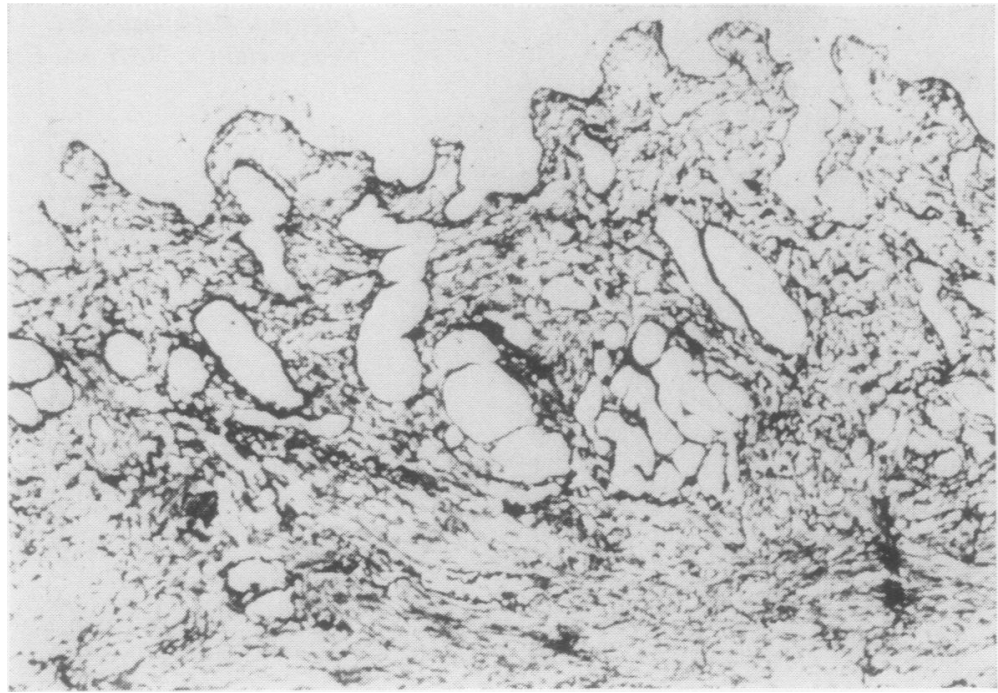

Figs. 14 and 15 Body and

pyloric mucosa.

Subepithelial and inter-tubular reticulin condensation and deposition. Compare with Figs. 2 and $5(\times 50$ reticulin stain).

Fig. 15. 
gland areas a felt-like mesh results when the reticulin fibres collapse together as the tubules disappear and new fibres are formed as part of the inflammatory reaction. In severe atrophy the junction between the muscularis mucosa and lamina propria is less well defined than normal and the whole of the normal reticulin pattern is obscured.

\section{Classification of Chronic Gastritis}

The classification proposed is based on establishing four biopsy features: (1) the mucosal type; (2) the grade of chronic gastritis; (3) the activity of gastritis; and (4) the presence and type of metaplasia.

\section{MUCOSAL TYPE}

Difficulties in recognizing mucosal type arise when severe gastritis is present and there is atrophy or metaplasia. When only pseudo-pyloric or intestinal metaplastic tubules remain, the mucosa cannot be classified but if residual body glands remain, their recognition being facilitated in Maxwell preparations, then the mucosa must be of body or transitional type. If all the tubules remaining are of 'pyloric' type the mucosa could have originated in any part of the stomach, because gastritis in pyloric or cardiac mucosa will be similar to gastritis with pseudopyloric metaplasia in body or transitional mucosa. The site of the biopsy specimen is fairly accurately located, except in stomachs altered by previous operations and in practice difficulty only arises in biopsy specimens from the lesser curve area, where even in normal stomach the demarcation of one region from its neighbour is often poorly defined. A helpful point in the differentiation of normal pyloric glands from pseudo-pyloric glands is that whilst the former may contain occasional parietal cells the latter do not.

\section{GRADE OF CHRONIC GASTRITIS}

In common with the majority of previous authors, two major subdivisions are advocated, namely, superficial gastritis and atrophic gastritis. In the former the inflammatory and reactive changes already outlined affect only the superficial epithelium, gastric pit region, and related lamina propria. Atrophic gastritis occurs if the changes affect the gland layer, and the difficult line of demarcation is between superficial gastritis and early atrophic gastritis, the later and more severe grades of atrophic gastritis being obvious. While deep extension of the inflammatory infiltrate around the tubules may be helpful, the only satisfactory criterion is recognition of atrophy of the tubules. In this respect the prepar- ations stained for reticulin are most valuable since loss of tubules, even in small numbers, is reflected by the changes in reticulin pattern already outlined. Atrophic gastritis could be classified by accurately quantitating the number of glands which remain but a convenient subdivision is into mild, moderate, and severe. If only one or two groups of tubules have disappeared, the mucosa is classified as showing mild atrophy; if all normal tubules are lost or only one or two groups remain, then the designation is severe; and all appearances between these two extremes are classed as moderate. It is important for this scheme that only normal glands be considered and those showing metaplasia be discounted.

In severe atrophic gastritis with widespread metaplasia, a negligible inflammatory cell infiltrate, atrophic lymphoid aggregates, and fatty infiltration of the lamina propria the appearances are often classified as gastric mucosal atrophy (Figs. 16 and 17).

\section{ACTIVITY OF GASTRITIS}

As already outlined, some biopsy specimens exhibit an invasion of polymorphs into and degenerative changes of the epithelial elements of the gastric mucosa. If this reflects an active stage of inflammatory destruction as seems likely, then clearly its presence should be brought into any scheme of classification. This activity could be recorded in a simple positive or negative fashion, a positive meaning that 'activity' was seen in some part of the biopsy specimens. A grading of activity could be achieved simply on the basis of whether it was diffuse throughout the mucosa or patchy in distribution. In mucosa with minimal epithelial degenerative changes and a slight chronic inflammatory infiltrate the appearance is recorded as quiescent. This quiescent phase is seen par excellence in mucosa with severe atrophy and metaplasia, ie, showing so-called gastric atrophy.

\section{METAPLASIA}

Intestinal metaplasia nearly always occurs in a mucosa which is the site of atrophic gastritis. Occasionally it is present in the superficial epithelium and pits in superficial gastritis, and very occasionally isolated islands are seen in otherwise normal mucosa. Pseudo-pyloric metaplasia, on the other hand, occurs only in atrophic gastritis. There is some evidence that pseudo-pyloric metaplasia may be reversible (Harvey, 1907). Both types should be recorded separately, and the degree to which they are present can be graded.

A full classification of chronic gastritis, therefore, based on the above principles, would be as follows: 


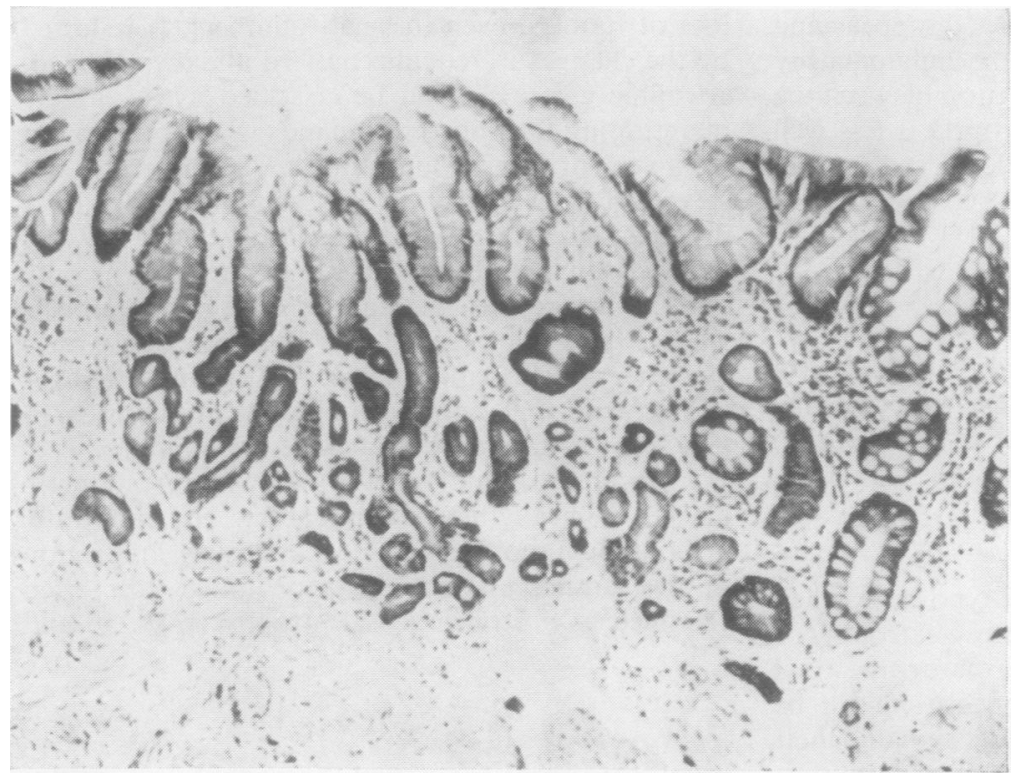

Figs. 16 and 17 Body mucosa. Gastric atrophy with partial and complete intestinal metaplasia. Note absence of epithelial degenerative changes and minimal cellular infiltrate of lamina propria $(\times 50 \mathrm{H}$ and $E$ ).

Fig. 16.

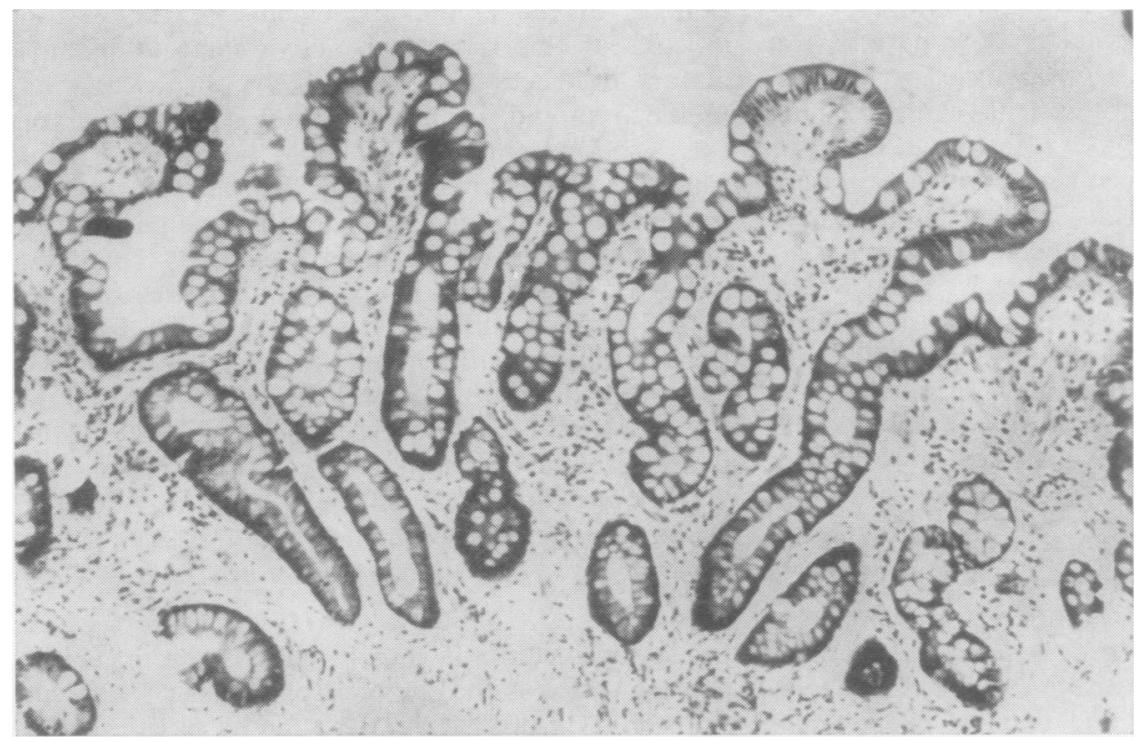

Fig. 17.

\begin{tabular}{|c|c|c|c|}
\hline Mucosal Type & Grade of Gastritis & & Metaplasia \\
\hline $\begin{array}{l}\text { Pyloric } \\
\text { Body }\end{array}$ & Superficial $\left\{\begin{array}{l}\text { Quiescent } \\
\text { Active } \\
\text { Mild }\end{array}\right.$ & Ouiescent & Pseudo-pyloric \\
\hline Cardiac & Atrophic $\left\{\begin{array}{l}\text { Moderate } \\
\text { Severe }\end{array}\right.$ & Active & Intestinal \\
\hline $\begin{array}{l}\text { Transitional } \\
\text { Indeterminate }\end{array}$ & & & \\
\hline
\end{tabular}

\section{Discussion}

In previous studies on gastritis it has been assumed that because two blind biopsy specimens reveal similar features, they reflect the state of the gastric mucosa as a whole. Such a claim is unjustified and the topographical location of chronic gastritis and 
its evolution in relation to possible aetiological factors and other diseases have clearly not been adequately studied. With the advent of the gastric fibrescope equipped with biopsy facilities this is now possible. Previous classifications of chronic gastritis, however, do not allow full use of all the information available in multiple biopsy specimens from the different areas of the stomach. The classification presented in this paper provides a means of allocating each biopsy specimen to one of the main types of gastric mucosa. Atrophy, active and quiescent stages of gastritis, and the presence of both types of metaplasia are recorded and it is possible, within the classification as a whole, to apply any form of quantitative assessment to any of the individual features. This classification is advocated for future studies dealing with the aetiology of chronic gastritis and its relationship to age, dyspepsia, anaemia, peptic ulcer, cancer, and autoimmune phenomena all of which need to be repeated using fibrescopic biopsy specimens from several sites in the stomach.
This work was supported by a Medical Research Council grant to R.W.

References

Davidson, W. M. B., and Markson, J. L. (1955). The gastric mucosa in iron deficiency anaemia. Lancet, 2, 639-643.

Gear, M. W. L., Truelove, S. C., and Whitehead R. (1971). Gastric ulcer and gastritis. Gut, 12, 639-645.

Harvey, B. C. H. (1907). A study of the structure of the gastric glands of the dog and of changes which they undergo after gastroenterostomy and occlusion of the pylorus. Amer. J. Anat., 6, 207-243.

James, K. R. (1967). A simple silver method for the demonstration of reticulin fibres. J. med. Lab. Technol., 24, 4951.

MacDonald, W. C., and Rubin, C. E. (1967). Gastric biopsy-a critical evaluation. Gastroenterology, 53, 143-170.

Maxwell, A. (1963). The Alcian dyes applied to gastric mucosa. Stain Technol., 38, 286-287.

Motteram, R. (1951). A biopsy study of chronic gastritis and gastric atrophy. J. Path. Bact., 63, 389-394.

Pearse, A. G. E., Coulling, I., Weaver, B., and Friesen, S. (1970). The endocrine polypeptide cells of the human stomach, duodenum and jejunum. Gut, 11, 649-658.

Schrager, J., Spink, R., and Mitra, S. (1967). The antrum in patients with duodenal and gastric ulcers. Gut, 8, 497-508.

Williams, A. W., Edwards, F., Lewis, T. H. C., and Coghill, N. F. (1957). Investigation of non-ulcer dyspepsia by gastric biopsy. Brit. med. J., 1, 372-377.

Wood, I. J., and Taft, L. I. (1958). Diffuse Lesions of the Stomach, p. 86. Arnold, London. 